publication of results and uniformity of standards) and the Committee on 'Emotional Integration', which considered the preparation of text-books, the role of student unions and the resolution of religious conflicts. It was recommended that all universities which make available a certain minimum number of places for students from other parts of India and those bearing denominational names should discard the denominational component of their title. The Committee on Standards of Education recommended an increase in the number of technical schools, polytechnies, trade schools, etc., and improvement of the student-teacher ratio to at least $1: 7$ or $1: 10$. English was considered the only appropriate medium of instruction in postgraduate education at present, and the Committee recommended that the University Grants Commission should play a more active part in the development of all higher education. Research centres should be built up around outstanding personalities.

\title{
THE CHALLENGE OF HUNGER
}

$\mathrm{T}$ HE greatest challenge that faces mankind to-day and in the coming decades is the problem of feeding the growing population of the world. While the world population is increasing at an unprecedented rate, food production in the areas of the world where most people do not have enough to eat is lagging. Thus, to-day, mankind as a wholo is not being adequately fed, and there is a population increase of such dimensions that by the end of this century - possibly earlier-the number of mouths to be fed will be more than double.

For several years the Food and Agriculture Organization of tho United Nations has pointed out the dangers inherent in this situation. It has stressed that food production as a whole, but especially in the underdeveloped and developing countries, is not increasing fast enough. The rate of populationgrowth in the developing countries is more than 2 per cent, while the volume of agricultural production is increasing at slightly loss than 3 per cent per annum -a margin that is clearly precarious. Any major set-back in agriculture in any part of the world, owing to elimatic or other natural factors, could quickly wipe out the gains which have been so painfully won.

Statisties set out by Dr. Binai Ranjan Sen, the director-general of the Food and Agrieulture Organization, reveal the realism of this warning. Estimates of world agricultural production in 1960-61 (excluding mainland China) show an increase of no more than 1 per cent over production in the previous seasonwhich is less than the estimated rate of population growth of 1.6 per cent. If mainland China is included in the world agricultural production figures, the total production of 1960-61 would probably be less than that of 1959-60 instead of a 1 per cent increase. Set-backs due to bad weather in several regions of the world indicate that the $1961-62$ production may again be small.

Since the Second World War there has been a great expansion in the production of food and agricultural products, but by far the largest part of this has taken place in Europe, in North America and Oceania. All theso are countries where standards of living are high and the people are well fed and adequately nourished. In the food-deficient regions of Africa, Asia and Latin America, the increases have so far barely kept pace with the population increase. Thus, although the Far East Region, which is the worst nourished and most populous area in the world, has had a good harvest for three successive years and, excluding mainland China, the 1960-61 food production per head has only brought consumption levels up to those of 1939.

In other words, improvements in diets which could have been expected as a result of increases in food. production have, in fact, been largely nullified by population increase. In Latin America, for example, per capita food production continues to lag behind pre-war levels. In the Near East, however, per capita production is now about 10 per cent greater than the low levels prevailing in the pre-war period. In Africa, a rather stationary situation prevailed with some ups and downs. These regional figures reveal wide differences among individual countries.

A statistical survey of the incidence of hunger and malnutrition was recently made by Dr. P. V. Sukhatme, director of the Statistics Division of the Food and Agriculture Organization, based on the international reference scale for calorie requirements and on the variation in energy expenditure among men of the reference age group. Applying the Food and Agriculture Organization calorie standards as a basis of comparison for the quantitative aspects of the diet, the study showed that calorie supplies in Europe, North America and Oceania are of the order of more than 3,100 calories per capita per day and exceed the requirements by about 20 per cent. In the Near East, Africa and Latin America, they are about equal to the requirements, amounting to some 2,400. In the Far East, the supplies are of the order of only 2,050 compared with a calorie requirement of some 2,300 . The supply thus falls short of the requirement by 11 per cent.

This gap is particularly striking when compared with the total calorie supplies of other regions. Thus, the shortage in the Far East is of a quantity large enough to feed the entire population of the Near East. Even for other regions whero the overall picture looks balanced, there are wide variations within the region. In the Near East, for example, there is apparently enough food in a group of countries where one-half of the population lives: the other half lives in a relatively poorer area. The calorie supplies of this area are only $2,100-2,200$ per capita per day. It is therefore justifiable to conclude that many millions of people in the world still go hungry at least for a part of their lives.

Thus, the recent study conducted by the Food and Agriculture Organization * has shown that the gap of 11 per cent between the calorie supplies and the calorie requirements in the Far East is shared by one-fifth to one-fourth of the population of the region. Since this region comprises half the total world population, it is clear that a conservative estimate of the proportion of undernourished in the world is between 10 and 15 per cent. In actual numbers this means that between 300 and 500 million go hungry for part of their lives, even in normal times.

* UNESCO Courier, July-August (1962). 